\title{
Moderate to vigorous physical activity participation associated with better quality of life among breast and colorectal cancer survivors in Korea
}

\author{
Ji-Hye Park ${ }^{1,4 \dagger}$, Dong Hoon Lee ${ }^{2 \dagger}$, Seung $\| \mathrm{Kim}^{3^{*}}$, Nam Kyu Kim ${ }^{3}$ and Justin Y. Jeon ${ }^{1,4,5,6^{*}}$
}

\begin{abstract}
Background: To investigate the association between physical activity (PA) and quality of life (QoL) among breast and colorectal cancer survivors in Korea.

Methods: A total of 224 cancer survivors (151 breast and 73 colorectal cancers) who completed treatments were recruited. We measured PA level with Godin Leisure-Time Exercise Questionnaire and QoL with European Organization for Research and Treatment of Cancer (EORTC) QLQ C-30.

Results: Moderate to vigorous PA was significantly correlated with global QoL $(r=.311, p<0.01)$, physical functioning $(r=.231, p<0.01)$, fatigue $(r=-.176, p<0.05)$, pain $(r=-.154, p<0.05)$, and dyspnea $(r=-.221, p<0.01)$ while no correlation was found between light PA and QoL after controlling for potential confounders. When we further divided our participants into four groups by total PA level, we found a strong linear dose-response relationship between higher total PA and better QoL outcomes $(p<.001)$. Compared with participants in the lowest quartile, those in the highest quartile had significantly better score in global QoL (65.8 \pm 2.7 vs. $77.6 \pm 2.8, p=0.003)$, physical functioning (67.2 \pm 2.3 vs. $85.3 \pm 2.4, p=0.007)$, fatigue ( $35.9 \pm 3.2$ vs. $23.6 \pm 3.2, p=0.008)$, pain $(22.7 \pm 3.3$ vs. $13.0 \pm 3.4, p=0.046)$, and dyspnea (13.7 \pm 2.5 vs. $5.9 \pm 2.6, p=0.034)$.
\end{abstract}

Conclusions: Higher PA level was associated with better QoL among breast and colorectal cancer survivors in Korea. Increasing PA levels should be included as one of important strategies to improve QoL in cancer survivors.

Keywords: Physical activity, Quality of life, Breast cancer, Colorectal cancer, Survivor, Korea

\section{Background}

Over 1 million cancer survivors are alive in Korea in 2016 [1] and cancer has been the leading cause of death in Korea since 1983 and is one of the most serious diseases [2]. Overall, the 5-year relative survival rate for

\footnotetext{
*Correspondence: skim@yuhs.ac; jjeon@yonsei.ac.kr

${ }^{\dagger} \mathrm{ji}$-Hye Park and Dong Hoon Lee contributed equally to this work.

${ }^{3}$ Department of Surgery, Yonsei University College of Medicine, Yonsei University, 50 Yonsei-ro, Seodaemun-Gu, Seoul, South Korea

'Department of Sport Industry Studies, Yonsei University, 50 Yonsei-ro, Seodaemun-Gu, Seoul, South Korea

Full list of author information is available at the end of the article
}

people diagnosed with cancer between 2012 and 2016 was $70.6 \%$, which represents an improved survival rate as compared with $41.2 \%$ for people diagnosed between 1993 and 1995 [1]. Cancer survivors report significantly lower levels of health-related quality of life (QoL) than non-cancer population [3, 4]. Cancer diagnosis is a major stressor resulting in considerable psychological suffering [5-7]. During and after cancer treatments, cancer patients frequently experience diverse physical and psychological symptoms including anxiety, fear, fatigue, pain, depression as well as decreases in overall functions

(c) The Author(s). 2020 Open Access This article is licensed under a Creative Commons Attribution 4.0 International License, which permits use, sharing, adaptation, distribution and reproduction in any medium or format, as long as you give appropriate credit to the original author(s) and the source, provide a link to the Creative Commons licence, and indicate if changes were made. The images or other third party material in this article are included in the article's Creative Commons licence, unless indicated otherwise in a credit line to the material. If material is not included in the article's Creative Commons licence and your intended use is not permitted by statutory regulation or exceeds the permitted use, you will need to obtain permission directly from the copyright holder. To view a copy of this licence, visit http://creativecommons.org/licenses/by/4.0/. The Creative Commons Public Domain Dedication waiver (http//creativecommons.org/publicdomain/zero/1.0/) applies to the data made available in this article, unless otherwise stated in a credit line to the data. 
[8-10]. Additionally, previous studies in diverse populations indicate that suicide is approximately twice as prevalent among patients with cancer compared with the general population [11-13].

Well-known way to improve mental health and QoL among cancer patients is through exercise and physical activity (PA). A systemic review reported that PA interventions significantly improved QoL in cancer survivors $[14,15]$. Additionally, PA participation has been associated with reduced cancer-specific and all-cause mortality in breast and colorectal cancer survivors $[16,17]$. Despite the growing evidence showing the benefits of exercise and PA on physical function, psychological health and prognosis and the safety of participating in exercise for cancer patients, many cancer patients still remain physically inactive $[16,18,19]$. Studies reported that $30-$ $47 \%$ of cancer survivors in the United States met the American College of Sports Medicine (ACSM)'s exercise recommendation $[20,21]$, while only $25.2 \%$ of Korean colorectal cancer survivors met the ACSM's exercise recommendations that is significantly lower than the percentage among the non-cancer population [22]. Although the benefit of PA is well known among cancer survivors, there is limited data on the relationship between PA participation and QoL among Korean cancer survivors. Therefore, the purpose of this study was to investigate the association between the level of selfreported PA and QoL in breast and colorectal cancer survivors in Korea.

\section{Methods}

\section{Study design}

Potential participants were screened for eligibility via a medical record review before their arrival at the clinic. Upon arrival at the clinic, oncologists asked patients if they were willing to participate in a study. The research coordinator explained the study in detail and obtained a written consent. Each participant completed PA and QoL questionnaires. This research was a cross-sectional study conducted at Shinchon Severance Hospital Cancer Clinic, in Seoul, Korea. The study was approved by the Institutional Review Board of the Yonsei University College of Medicine.

\section{Participants and procedure of the study}

The eligibility criteria for the study were: (1) aged over 18 years old, (2) completed primary and adjuvant treatments for colorectal and breast cancer (stage 0-IV), (3) ability to read and speak Korean. Participants who had any of the following characteristics or disorders were excluded from the study: participants who had a prior history of any cancer (except breast and colorectal cancer), current psychiatric illness, cardiovascular disease and/or diabetes, or had any other condition (e.g. neurological, orthopedic disorders) that made them unsuitable for participation in this study. Based on prior literature [23], we used G*Power to calculate required study sample size to detect small differences in mean QoL scores across physical activity groups given $80 \%$ power in a two-sided test with $\alpha$-level of 0.05 . In the current study, a total of 232 breast and colorectal cancer patients were initially recruited and screened for eligibility between 2013 and 2014. Among these participants, we excluded 8 cancer patients who had a prior history of other cancers and 224 eligible cancer patients (96.6\%) agreed to participate in the study and completed PA and QoL questionnaires. The final analysis included 224 breast and colorectal cancer patients.

\section{Main outcome measurement $P A$ questionnaire}

The amount of PA participation was assessed by the leisure score index (LSI) using the Godin Leisure-Time Exercise Questionnaire [24, 25]. Participants were asked to report their average weekly frequency and duration of light, moderate, or vigorous intensity exercise. The weekly exercise intensity was categorized as follows: Light (3 metabolic equivalent task (MET)). Moderate (5 MET), and Vigorous (9 MET). Of note, a MET indicates the ratio of the rate of energy expenditure during a specific activity to the rate of energy expenditure at rest. The summary totals for each intensity time were calculated, along with the total exercise time within a week.

Based on the PA information, we also calculated the percentage of participants meeting the ACSM PA Guidelines for Americans for cancer survivors $(\geq 150$ $\mathrm{min} / \mathrm{wk}$. of moderate-intensity or $\geq 75 \mathrm{~min} / \mathrm{wk}$. of vigorous-intensity aerobic exercise or an equivalent combination of moderate- and vigorous intensity aerobic exercise). The ACSM PA guideline has been widely used in many countries, including Asian countries, for prevention of cancer and other diseases and the PA guideline has shown similar benefits for non-Asian and Asian individuals [26].

\section{QoL questionnaire}

QoL was assessed with the European Organization for Research and Treatment of Cancer (EORTC) QLQ C-30 instrument, which has been widely used to assess QoL of cancer survivors [27, 28]. It is a 30 -item measure of QoL consisting of five multi-item functional scales (physical, role, emotional, cognitive, social), three multiitem symptom scales (fatigue, pain, nausea and vomiting), six single-item symptom scales (dyspnea, insomnia, appetite loss, constipation, diarrhea, and financial difficulties), and one multi-item QoL scale. The scores of scales range from 0 to 100 , with higher scores representing higher QoL. 


\section{Statistical analysis}

All data were analyzed using SPSS 21.0 software (SPSS Inc., Chicago, IL, USA). Descriptive statistics were used to present the demographic and medical characteristics and physical activity level of the participants. Spearman correlation analyses were used to test for a potential relationship between PA and QoL. For the primary analysis, we categorized participants into quartiles based on their total PA level. ANCOVA was used to examine the differences in QoL outcomes across the quartiles of total PA level after adjusting for important demographic and cancer treatment-related factors including age, BMI, gender, marital status, income, education, types of cancer, and time since surgery. These potential confounders were chosen a priori based prior literature on physical activity and quality of life in cancer survivors [14, 15]. We further conducted subgroup analyses to explore whether the association between PA and QoL differs by potential effect modifiers including age, BMI, sex, marital status, income, education, types of cancer, time since surgery. We classified participants into two groups based on the ACSM PA guideline for the subgroup analyses. Interactions were tested by including interaction terms for PA and the potential effect modifiers in the model. A multiple linear regression analysis was performed to determine the association between QoL and PA and demographic/treatment factors. In this model, QoL was included as a dependent variable and independent variables we considered were age, BMI, gender, marital status, income, education, types of cancer, time since surgery, and total PA time. $P$-values less than 0.05 were considered statistically significant.

\section{Results}

\section{Characteristics of participants}

The participant's demographic and medical characteristics are shown in Table 1 . There were 224 participants (45 males and 179 females; 151 breast and 73 colorectal cancer patients) who completed questionnaires. Mean age was $54.4 \pm 7.8$ years old for males and $51.5 \pm 8.2$ years old for females. All participants were diagnosed with stage 0 to IV breast or colorectal cancer. (Table 1).

The average weekly total PA participation was $346.1 \pm$ 316.6 min while PA of male participants were substantially higher than female participants $(449.5 \pm 397.6$ vs $320.1 \pm 288.3)$. Sixty three out of $224(27.7 \%)$ cancer survivors met the ACSM PA guidelines for cancer survivors (Table 2).

\section{Relationship between PA participation and QoL}

To examine the association between the amount of PA participation and QoL, we studied whether the amount of PA and overall QoL as well as functional and symptom scale of QoL would be associated according to the intensity of PA; moderate to vigorous PA, light PA and total PA with and without adjustment for potential confounders. Overall QoL was significantly associated with the amount of moderate to vigorous PA and total PA with and without adjustment of potential confounding variables.

The amount of moderate to vigorous PA participation was significantly correlated with physical functioning $(r=0.292, p<0.01)$, emotional functioning $(r=0.195$, $p<0.01)$, cognitive functioning $(r=0.175, p<0.01)$, fatigue $(r=-.263, p<0.01)$, pain $(r=-.220, p<0.01)$, dyspnea $(r=-.176, p<0.01)$, insomnia $(r=-.132, p<0.05)$, appetite loss $(r=-.188, p<0.01)$, and constipation $(r=$ $-.144, p<0.05)$. When correlation analyses were further performed after adjustment for potential confounding factors, the amount of moderate to vigorous PA participation was still significantly correlated with physical functioning $(r=.231, p<0.01)$, emotional functioning $(r=0.155, p<0.05)$, fatigue $(r=-.176, p<0.05)$, pain $(r=$ $-.154, p<0.05)$, and dyspnea $(r=-.221 p<0.01)$ (Table 3).

To further analyze the relationship between the amount total PA participation and QoL, participants were divided into four groups (Quartile) and their QoL were compared. Overall, we found a strong linear dose response between higher PA and better QoL in cancer survivors $(p<.001)$. Compared with participants in the lowest quartile of total PA, participants in the higher quartile of PA had significantly higher scores in global QoL (Quartile 1: $65.8 \pm 2.7$ vs. Quartile 4: $77.6 \pm 2.8, p=$ 0.003 ) and physical functioning (Quartile 1: $67.2 \pm 2.3$ vs. Quartile 4: $85.3 \pm 2.4, p=0.007$ ) while significantly lower scores in fatigue (Quartile 1: $35.9 \pm 3.2$ vs. Quartile 4: $23.6 \pm 3.2, p=0.008$ ), pain (Quartile 1: $22.7 \pm 3.3$ vs. Quartile 4: $13.0 \pm 3.4, p=0.046$ ) and dyspnea (Quartile 1: $13.7 \pm 2.5$ vs. Quartile 4: $5.9 \pm 2.6, p=0.034$ ) after adjustment of potential confounding variables (Supplementary Table 1).

For the subgroup analyses, we divided our participants into two groups; who meet the ACSM PA guideline and do not meet the ACSM PA guideline. In these analyses, we further divided our participants by potential effect modifiers and compared their QoL between subgroups. Compared with participants diagnosed with stage 0-I cancer, meeting the ACSM PA guideline was more strongly associated with better QoL among participants diagnosed with stage II-IV cancer ( $\mathrm{P}$ for interaction $=$ 0.04). Overall, participants who met the ACSM PA guideline had better QoL, regardless of age, gender, BMI, type of cancer, time since surgery, monthly household income and education level (Table 4).

Multiple regression analyses with QoL as dependent variable and gender, age, types of cancer, stage, time since surgery, income, education, BMI and total PA as 
Table 1 Characteristics of breast and colorectal cancer survivors $(N=224)$

\begin{tabular}{|c|c|c|c|c|c|c|}
\hline \multirow[t]{2}{*}{ Variables } & \multicolumn{2}{|c|}{ Male $(N=45)$} & \multicolumn{2}{|c|}{ Female $(N=179)$} & \multicolumn{2}{|c|}{ Total $(N=224)$} \\
\hline & $\mathrm{N}$ & $\%$ & $\mathrm{~N}$ & $\%$ & $\mathrm{~N}$ & $\%$ \\
\hline \multicolumn{7}{|l|}{$\overline{\text { Age }}$} \\
\hline$<60 \mathrm{yrs}$ & 34 & 15.2 & 146 & 65.2 & 180 & 80.4 \\
\hline$\geq 60 \mathrm{yrs}$ & 11 & 4.9 & 33 & 14.7 & 44 & 19.6 \\
\hline \multicolumn{7}{|l|}{ BMl } \\
\hline$<23 \mathrm{~kg} / \mathrm{m}^{2}$ & 11 & 5.4 & 105 & 51.7 & 116 & 57.1 \\
\hline$\geq 23 \mathrm{~kg} / \mathrm{m}^{2}$ & 24 & 11.8 & 63 & 31 & 87 & 42.9 \\
\hline \multicolumn{7}{|l|}{ Material status } \\
\hline Married & 44 & 19.7 & 148 & 66.4 & 912 & 86.1 \\
\hline Single & 0 & 0 & 9 & 4.0 & 9 & 4.0 \\
\hline Widowed & 0 & 0 & 8 & 3.6 & 8 & 3.6 \\
\hline Divorced & 1 & 0.4 & 13 & 5.8 & 14 & 6.3 \\
\hline \multicolumn{7}{|l|}{ Average monthly household income status } \\
\hline$\leq \$ 1000$ & 1 & 0.5 & 21 & 9.6 & 22 & 10.1 \\
\hline$\$ 1001-\$ 3000$ & 15 & 6.9 & 53 & 24.3 & 68 & 31.2 \\
\hline$\$ 3001-\$ 5000$ & 14 & 6.4 & 61 & 28 & 75 & 34.4 \\
\hline$\geq \$ 5001$ & 15 & 6.9 & 38 & 17.4 & 53 & 24.3 \\
\hline \multicolumn{7}{|l|}{ Education } \\
\hline Middle school graduate or less & 5 & 2.2 & 35 & 15.7 & 40 & 17.9 \\
\hline High school gradate & 18 & 8.1 & 75 & 33.6 & 93 & 41.5 \\
\hline University/college & 14 & 6.3 & 53 & 23.8 & 67 & 30 \\
\hline Higher degree than university/college & 8 & 3.6 & 15 & 6.7 & 23 & 10.3 \\
\hline \multicolumn{7}{|l|}{ Occupation } \\
\hline Professional/business & 13 & 5.8 & 11 & 4.9 & 24 & 10.8 \\
\hline Office & 3 & 1.3 & 10 & 4.5 & 13 & 5.8 \\
\hline Sale/Technical & 3 & 1.3 & 8 & 3.6 & 11 & 4.9 \\
\hline Production/Labor & 0 & 0 & 2 & 0.9 & 2 & 0.9 \\
\hline Service & 4 & 1.8 & 11 & 4.9 & 15 & 6.7 \\
\hline Self employed & 8 & 3.6 & 19 & 8.5 & 27 & 12.1 \\
\hline Education/government & 3 & 1.3 & 2 & 0.9 & 5 & 2.2 \\
\hline Housewife & 0 & 0 & 91 & 40.8 & 91 & 40.8 \\
\hline Unemployed & 9 & 4.0 & 18 & 8.1 & 27 & 12.1 \\
\hline Other & 2 & 0.9 & 6 & 2.7 & 8 & 3.6 \\
\hline \multicolumn{7}{|l|}{ Types of cancer } \\
\hline Breast cancer & 0 & 0 & 151 & 67.4 & 151 & 67.4 \\
\hline Colorectal cancer & 45 & 20.1 & 28 & 12.5 & 73 & 32.6 \\
\hline \multicolumn{7}{|l|}{ Stages of caner } \\
\hline Stage 0 & 0 & 0 & 3 & 1.4 & 3 & 1.4 \\
\hline Stage I & 16 & 7.7 & 75 & 36.2 & 91 & 44.0 \\
\hline Stage ॥ & 9 & 4.3 & 58 & 28 & 67 & 32.4 \\
\hline Stage III & 14 & 6.8 & 26 & 12.6 & 40 & 10.3 \\
\hline Stage IV & 3 & 1.4 & 3 & 1.4 & 6 & 2.9 \\
\hline \multicolumn{7}{|l|}{ Time since surgery } \\
\hline$<2 \mathrm{yrs}$ & 26 & 12.0 & 86 & 39.8 & 112 & 51.9 \\
\hline$\geq 2 \mathrm{yrs}$ & 19 & 8.8 & 85 & 39.4 & 104 & 48.1 \\
\hline
\end{tabular}

Abbreviation: $B M I$ body mass index 
Table 2 Physical activity levels of breast and colorectal cancer survivors in Korea

\begin{tabular}{|c|c|c|}
\hline Variables & Mean (SD) & Median (IQR) \\
\hline \multicolumn{3}{|l|}{ Male $(N=45)$} \\
\hline \multicolumn{3}{|l|}{ PA time (min/week) } \\
\hline Vigorous intensity PA & $95.1 \pm 201.5$ & $0(0-120)$ \\
\hline Moderate intensity PA & $206.6 \pm 367.1$ & $0(0-280)$ \\
\hline Light intensity PA & $147.8 \pm 189.5$ & $30(0-270)$ \\
\hline Total PA & $449.5 \pm 397.6$ & $385(210-630)$ \\
\hline Meeting the ACSM PA guideline, n (\%) & $27(12.1)$ & - \\
\hline \multicolumn{3}{|l|}{ Female $(N=179)$} \\
\hline \multicolumn{3}{|l|}{ PA time (min/week) } \\
\hline Vigorous intensity PA & $9.3 \pm 45.1$ & $0(0-0)$ \\
\hline Moderate intensity PA & $80.3 \pm 214.6$ & $0(0-0)$ \\
\hline Light intensity PA & $230.5 \pm 109.7$ & $180(75-330)$ \\
\hline Total PA & $320.1 \pm 288.3$ & $270(135-420)$ \\
\hline Meeting the ACSM PA guideline, $\mathrm{n}(\%)$ & $35(15.6)$ & - \\
\hline \multicolumn{3}{|l|}{ Total $(\mathrm{N}=224)$} \\
\hline \multicolumn{3}{|l|}{ PA time (min/week) } \\
\hline Vigorous intensity PA & $26.5 \pm 104.0$ & $0(0-0)$ \\
\hline Moderate intensity PA & $105.7 \pm 256.8$ & $0(0-61)$ \\
\hline Light intensity PA & $213.0 \pm 208.1$ & $180(0-309)$ \\
\hline Total PA & $346.1 \pm 316.6$ & $290(143-450)$ \\
\hline Meeting the ACSM PA guideline, $\mathrm{n}(\%)$ & $63(27.7)$ & - \\
\hline
\end{tabular}

Abbreviation: ACSM American College of Sport Medicine, IQR interquartile range, $P A$ physical activity, $S D$ standard deviation

ACSM PA guideline: $\geq 150 \mathrm{~min} / \mathrm{wk}$. of moderate-intensity or $\geq 75 \mathrm{~min} / \mathrm{wk}$. of vigorous-intensity aerobic exercise or an equivalent combination of moderateand vigorous intensity aerobic exercise

independent variables showed that only total PA amount was a significant predictor of QoL $(=0.25, p=<0.01)$ (Table 5).

\section{Discussion}

This cross-sectional study was to examine whether the amount of self-reported PA is associated with QoL among Korean breast and colorectal cancer survivors. As hypothesized, higher amount of moderate to vigorous and total PA (sum of light, moderate, and vigorous PA) were significantly associated with higher QoL while no association between the amount of light PA and any of the QoL variables was shown. These associations were supported when our participants were divided into quartiles and their QoL outcomes were compared across quartiles. Compared with participants in the 1st quartile (the least active), participants in the 4th quartile had 11.8 point (65.8 vs. 77.6 point) higher scores in global QoL, clinically meaningful moderate differences [29] .

Findings from the current study are supported by previous studies reported that moderate to vigorous PA is associated with health-related QoL among colorectal cancer survivors [30, 31]. Moreover, accumulating evidence suggests that participation of PA contributes to improved QoL through positive changes in physical, psychological, social and spiritual factors [32, 33]. What is unique and interesting about our finding is that light PA was not associated with any of QoL variables. We have previously demonstrated that under cancer treatment, moderate to vigorous PA participation decreases while light PA increases among Korean colorectal cancer survivors [22]. Current ACSM PA recommendations for cancer survivors focus on accumulating adequate level of moderate to vigorous PA level (overall level of weekly activity of $150 \mathrm{~min}$ of moderate-intensity exercise or $75 \mathrm{~min}$ of vigorous-intensity exercise or an equivalent combination). Cochrane Review revealed that PA at moderate to vigorous intensity provides greater health benefits than low-intensity PA [34]. Interestingly, our study found that significantly higher QoL score in the 4th quartile of PA group compared with 1st quartile of PA group. Participants in the 4th quartile may have been only group which met the ACSM guidelines for cancer survivors (mean of moderate to vigorous PA Q1: $5.5 \mathrm{~min} / \mathrm{wk}$., Q2: 31.4 min/wk., Q3: $109.1 \mathrm{~min} / \mathrm{wk} .$, Q4: $368.9 \mathrm{~min} / \mathrm{wk}$ ) but we still observed better QoL with higher PA in the second and third quartiles. Therefore, it is important to encourage moderate to vigorous PA among cancer survivors to improve QoL.

In order to better understand our data, we conducted subgroup analyses by potential effect modifiers and found that meeting the ACSM PA guideline was more closely associated with better global QoL among participants whose cancer stage was greater than stage II. Normally, cancer patients with stage 0-II undergo surgery and some receive additional therapy but cancer patients above stage II most often receive radiation and/or chemotherapy in addition to surgery. Patients undergoing radiation and chemotherapy treatment experience decline in their perceived QoL during treatment. This finding suggests that cancer survivors above stage II could benefit more from participating PA to improve QoL.

Given the importance of regular PA for disease prevention and health promotion [35], the low number of participants meeting the ACSM PA guideline is of concern. Our study found only $27.7 \%$ of cancer survivors met the exercise recommendations of the ACSM. Consistent with our findings, Chung et al. reported that $25.2 \%$ of Korean colorectal cancer patients met the ACSM PA guideline [22]. However, other studies have reported higher percentage of cancer survivors who met the ACSM PA guideline in other populations. Irwin et al., [18] reported 32\% of 
Table 3 Spearman correlation between physical activity levels and quality of life (EORTC QLQ C-30) in breast and colorectal cancer survivors in Korea

\begin{tabular}{|c|c|c|c|c|c|c|c|}
\hline & & Intensity of PA & & & Intensity of PA (adjusted) & & \\
\hline & & Moderate to vigorous PA & Mild PA & Total PA & Moderate to vigorous PA & Mild PA & Total PA \\
\hline$\overline{\text { QoL }}$ & & $.267^{* *}$ & -.007 & $.231^{* *}$ & $.311^{* *}$ & -.031 & $.249^{* *}$ \\
\hline Functional scales & Physical functioning & $.292^{* *}$ & .029 & $.277^{* *}$ & $.231^{* *}$ & .082 & $.251^{* *}$ \\
\hline & Role functioning & .117 & .096 & $.166^{*}$ & .043 & $.159^{*}$ & .136 \\
\hline & Emotional functioning & $.195^{* *}$ & -.050 & $.139^{*}$ & $.155^{*}$ & -.030 & .115 \\
\hline & Cognitive functioning & $.175^{* *}$ & -.049 & .122 & .106 & -.040 & .067 \\
\hline & Social functioning & .023 & -.010 & .014 & -.030 & -.023 & -.041 \\
\hline Symptom scales & Fatigue & $-.263^{* *}$ & -.064 & $-0.275^{* *}$ & $-.176^{*}$ & -.094 & $-.210^{* *}$ \\
\hline & Nausea and vomiting & -.071 & -.011 & -.070 & .002 & -.020 & -.011 \\
\hline & Pain & $-.220^{* *}$ & .060 & $-.155^{*}$ & $-.154^{*}$ & -.022 & -.147 \\
\hline & Dyspnea & $-.176^{* *}$ & .075 & -.106 & $-.221^{* *}$ & -.024 & $-.206^{* *}$ \\
\hline & Insomnia & $-.132^{*}$ & -.032 & $-.138^{*}$ & -.117 & -.076 & -.149 \\
\hline & Appetite loss & $-.188^{* *}$ & .042 & $-.138^{*}$ & -.126 & -.016 & -.119 \\
\hline & Constipation & $-.144^{*}$ & -.029 & $-.146^{*}$ & -.139 & .013 & -.113 \\
\hline & Diarrhea & .112 & $-.149^{*}$ & .002 & .114 & -.131 & .042 \\
\hline & Financial difficulties & -.041 & -.022 & -.051 & -.072 & -.003 & -.064 \\
\hline
\end{tabular}

Abbreviation: EORTC QLQ, European Organization for Research and Treatment of Cancer Quality of Life Questionnaire, $P A$ physical activity, QoL quality of life

${ }^{a}$ Adjusted for age, BMl, sex, marital status, income, education, cancer type, stage of cancer, time since surgery, ${ }^{*} P<.05,{ }^{* *} P<0.01$

Table 4 Adjusted mean (95\% Cl) of quality of life (QoL) according to the ACSM's physical activity guideline by subgroups of breast and colorectal cancer survivors in Korea

\begin{tabular}{|c|c|c|c|}
\hline & \multicolumn{2}{|c|}{ ACSM PA guideline } & \multirow{2}{*}{$\begin{array}{l}P \\
\text { interaction }\end{array}$} \\
\hline & Not meeting & Meeting & \\
\hline \multicolumn{4}{|l|}{$\overline{\text { Age }}$} \\
\hline$<60 \mathrm{yrs}$ & $65.4(61.9-69.0)$ & $79.2(73.4-84.9)^{*}$ & \multirow[t]{2}{*}{0.42} \\
\hline$\geq 60 \mathrm{yrs}$ & $72.0(64.8-79.1)$ & $78.3(64.6-92.1)$ & \\
\hline \multicolumn{4}{|l|}{ Gender } \\
\hline Male & $64.5(53.1-76.0)$ & $70.8(60.7-80.8)$ & \multirow[t]{2}{*}{0.15} \\
\hline Female & $67.8(64.3-71.2)$ & $82.2(75.1-89.3)^{*}$ & \\
\hline \multicolumn{4}{|l|}{ BMI } \\
\hline$<23 \mathrm{~kg} / \mathrm{m}^{2}$ & $66.0(61.9-67.0)$ & $82.7(63.4-73.3)^{*}$ & \multirow[t]{2}{*}{0.12} \\
\hline$\geq 23 \mathrm{~kg} / \mathrm{m}^{2}$ & $68.3(63.4-73.3)$ & $75.7(68.3-83.1)$ & \\
\hline \multicolumn{4}{|l|}{ Types of Cancer } \\
\hline Breast Cancer & $66.3(62.1-70.5)$ & $80.1(72.6-87.5)^{*}$ & \multirow[t]{2}{*}{0.33} \\
\hline Colorectal Cancer & $68.6(61.7-75.5)$ & $77.4(65.2-89.5)$ & \\
\hline \multicolumn{4}{|l|}{ Stages of cancer } \\
\hline$\leq$ Stage $\|$ & $67.7(64.1-71.4)$ & $76.6(70.9-82.4)^{*}$ & \multirow[t]{2}{*}{0.04} \\
\hline$>$ Stage II & $63.8(57.7-70.0)$ & $90.0(78.0-101.9)^{*}$ & \\
\hline \multicolumn{4}{|l|}{ Time since surgery } \\
\hline$<2$ yrs & $66.7(62.4-70.9)$ & $76.1(68.7-83.5)^{*}$ & \multirow[t]{2}{*}{0.27} \\
\hline$\geq 2 \mathrm{yrs}$ & $67.1(62.5-71.7)$ & $82.2(74.5-90.0)^{*}$ & \\
\hline \multicolumn{4}{|c|}{ Average monthly household income status } \\
\hline$\leq \$ 3000$ & $63.1(58.0-68.2)$ & $77.6(65.3-73.9)^{*}$ & \multirow[t]{2}{*}{0.54} \\
\hline$>3000$ & $69.6(65.3-73.9)$ & $80.0(73.1-86.9)^{*}$ & \\
\hline \multicolumn{4}{|l|}{ Education } \\
\hline$\leq$ High school graduate & $66.1(61.9-70.2)$ & $80.9(74.0-87.7)^{*}$ & \multirow[t]{2}{*}{0.21} \\
\hline > High school graduate & $68.2(63.8-73.5)$ & $76.1(67.8-84.4)$ & \\
\hline
\end{tabular}

Abbreviation: ACSM American College of Sport Medicine, BMI body mass index, PA physical activity

All models were adjusted for age, BMI, gender, marital status, income, education, types of cancer, time since surgery, ${ }^{*}$ Significantly different from Not meeting ACSM guideline $(P<0.05)$ 
Table 5 Multiple regression analysis of quality of life as a dependent variable

\begin{tabular}{|c|c|c|c|c|c|}
\hline Dependent variable & Variables & & SE & Standardized & $P$-value \\
\hline \multirow[t]{9}{*}{$\overline{\mathrm{QoL}}$} & Gender & 2.58 & 5.16 & .06 & .44 \\
\hline & Age & -.14 & .18 & -.06 & .43. \\
\hline & Types of cancer & 1.62 & 4.45 & .07 & .39 \\
\hline & Stages of cancer & -2.16 & 1.59 & -.11 & .18 \\
\hline & Time since surgery & .04 & .09 & .04 & .61 \\
\hline & Income & 1.52 & .84 & .16 & .07 \\
\hline & Education & .19 & 1.92 & .01 & .92 \\
\hline & $\mathrm{BMl}$ & .38 & .45 & .07 & .45 \\
\hline & Total PA & .01 & .00 & .25 & $<0.01$ \\
\hline
\end{tabular}

Abbreviation: $B M I$ body mass index, $P A$ physical activity, QoL quality of life, $S E$ standard error

Gender, age, BMI, marital status, income, education, types of cancer, time since surgery, total PA count for quality of life by $8.6 \%\left(R^{2}=0.043, F-v a l u e=0.05\right)$

breast cancer survivors and Blanchard et al. reported, [36] $30-47 \%$ of cancer survivors met the ACSM PA guideline. Recently, we have reported that oncologists' PA recommendation to their cancer survivors when given with pedometer and exercise diary significantly increased cancer survivors' PA participation [37]. Therefore, oncologists should team up with exercise specialists to provide proper and effective strategies to increase PA level of cancer survivors.

One of the limitations of our study is the nature of cross-sectional study that we cannot draw cause and effect conclusion. We may not be able to say higher PA level resulted in improved QoL since we cannot eliminate the possibility that those with higher QoL might have been in better physical condition which make them possible to participate in moderate to vigorous PA. To reduce this concern, we further analyzed our data after controlling for important sociodemographic and treatment related confounders and still found significant associations between the amount of PA and QoL. Furthermore, our multiple regression analysis also showed that only PA was a significant predictor of global QoL, suggesting the importance of PA. However, we suggest the need to further investigate the effect of moderate to vigorous exercise on QoL in a large randomized controlled trial among Korean cancer survivors. There are other limitations in our study. The reliance on self-report rather than objective measure of exercise behaviors may lead to imprecise measurements. However, use of accelerometer may also have limitation that predefined moderate to vigorous PA measured by accelerometer may not truly reflect PA levels of cancer survivors [38]. Moreover, our study sample was single clinic-based rather than population-based. Our study participants (particularly colorectal cancer patients) were younger than the general Korean cancer patients [39] which may reduce the generalizability of the findings to all breast and colorectal cancer survivors.

In conclusion, we found that increased moderate to vigorous PA participation was associated with higher QoL in breast and colorectal cancer survivors in Korea while no association was found between light PA and QoL. When cancer survivors can safely participate in PA with higher intensity, moderate PA should be recommended to improve QoL.

\section{Supplementary information}

Supplementary information accompanies this paper at https://doi.org/10 1186/s12885-020-06819-z.

Additional file 1: Table S1. Adjusted mean of quality of life (QoL) factors across quartiles of total physical activity levels in breast and colorectal cancer survivors in Korea.

\section{Abbreviations}

ACSM: American College of Sports Medicine; BMI: Body mass index; EORTC: European Organization for Research and Treatment of Cancer; PA: Physical activity; QoL: Quality of life

\section{Acknowledgements}

Not applicable

Authors' contributions

JHP and JYJ designed the study. SIK and NKK collected the data. JHP, DHL and JYJ conducted statistical analyses and wrote the manuscript. All authors revised and approved the final manuscript.

\section{Funding}

This study was supported by a grant from the National R\&D Program for Cancer Control, Ministry of Health \& Welfare, Republic of Korea (HA16C0012) and the Ministry of Education of the Republic of Korea and the National Research Foundation of Korea (NRF-2015S1A5B8036349). The funders had no role in the design of the study and collection, analysis, and interpretation of data and in writing the manuscript.

\section{Availability of data and materials}

The datasets used and/or analysed during the current study are available from the corresponding author on reasonable request.

\section{Ethics approval and consent to participate}

This study was approved by the Institutional Review Board of the Yonsei University College of Medicine, and a written consent was obtained from all participants. 


\section{Consent for publication}

Not applicable.

\section{Competing interests}

The authors declare that they have no competing interests.

\section{Author details}

'Department of Sport Industry Studies, Yonsei University, 50 Yonsei-ro, Seodaemun-Gu, Seoul, South Korea. ${ }^{2}$ Department of Nutrition, Harvard T.H. Chan School of Public Health, Boston, MA, USA. ${ }^{3}$ Department of Surgery, Yonsei University College of Medicine, Yonsei University, 50 Yonsei-ro, Seodaemun-Gu, Seoul, South Korea. ${ }^{4}$ Frontier research institute of Convergence Sports Science, Yonsei University, Seoul, South Korea. ${ }^{5}$ Cancer Prevention Center, Yonsei Cancer Center, Yonsei University College of Medicine, Seoul, South Korea. ${ }^{6}$ The Institute of Convergence Science, Yonse University, Seoul, South Korea.

\section{Received: 5 July 2019 Accepted: 2 April 2020}

\section{Published online: 01 May 2020}

\section{References}

1. Jung KW, Won YJ, Kong HJ, Lee ES: Cancer Statistics in Korea: Incidence, Mortality, Survival, and Prevalence in 2016. (2005-9256 (Electronic)).

2. Yoon SJ, Bae SC, Lee SI, Chang H, Jo HS, Sung JH, Park JH, Lee JY, Shin Y Measuring the burden of disease in Korea. J Korean Med Sci. 2007;22(3): $518-23$

3. Baker F, Denniston M, Haffer SC, Liberatos P. Change in health-related quality of life of newly diagnosed cancer patients, cancer survivors, and controls. Cancer. 2009:115(13):3024-33.

4. Baker F, Haffer SC, Denniston M. Health-related quality of life of cancer and noncancer patients in Medicare managed care. Cancer. 2003;97(3):674-81.

5. Nasseri K, Mills PK, Mirshahidi HR, Moulton LH. Suicide in cancer patients in California, 1997-2006. Arch Suicide Res. 2012;16(4):324-33.

6. Fang F, Fall K, Mittleman MA, Sparen P, Ye W, Adami HO, Valdimarsdottir U. Suicide and cardiovascular death after a cancer diagnosis. N Engl J Med. 2012;366(14):1310-8.

7. Shim EJ, Park JH. Suicidality and its associated factors in cancer patients: results of a multi-center study in Korea. Int J Psychiatry Med. 2012;43(4):381403.

8. Arndt V, Merx H, Stegmaier C, Ziegler H, Brenner H. Quality of life in patients with colorectal cancer 1 year after diagnosis compared with the general population: a population-based study. J Clin Oncol. 2004;22(23):4829-36.

9. Montazeri A, Vahdaninia M, Harirchi I, Ebrahimi M, Khaleghi F, Jarvandi S. Quality of life in patients with breast cancer before and after diagnosis: an eighteen months follow-up study. BMC Cancer. 2008;8(1):330

10. Wu H-S, Harden JK. Symptom burden and quality of life in survivorship: a review of the literature. Cancer Nurs. 2015;38(1):E29-54.

11. Ahn E, Shin DW, Cho SI, Park S, Won YJ, Yun YH. Suicide rates and risk factors among Korean Cancer patients, 1993-2005. Cancer Epidem Biomar. 2010:19(8):2097-105

12. Mann JJ. A current perspective of suicide and attempted suicide. Ann Intern Med. 2002;136(4):302-11.

13. Misono S, Weiss NS, Fann JR, Redman M, Yueh B. Incidence of suicide in persons with cancer. J Clin Oncol. 2008;26(29):4731-8.

14. Buffart LM, Kalter J, Sweegers MG, Courneya KS, Newton RU, Aaronson NK Jacobsen PB, May AM, Galvão DA, Chinapaw MJ. Effects and moderators of exercise on quality of life and physical function in patients with cancer: an individual patient data meta-analysis of 34 RCTs. Cancer Treat Rev. 2017;52 91-104

15. Gerritsen JK, Vincent AJ. Exercise improves quality of life in patients with cancer: a systematic review and meta-analysis of randomised controlled trials. Br J Sports Med. 2016;50(13):796-803.

16. Ballard-Barbash R, Friedenreich CM, Courneya KS, Siddiqi SM, McTiernan A, Alfano CM. Physical activity, biomarkers, and disease outcomes in cance survivors: a systematic review. J Natl Cancer Inst. 2012;104(11):815-40.

17. Je Y, Jeon JY, Giovannucci EL, Meyerhardt JA. Association between physical activity and mortality in colorectal cancer: a meta-analysis of prospective cohort studies. Int J Cancer J Int du Cancer. 2013:133(8):1905-13.

18. Irwin ML, Mctiernan A, Bernstein L, Gilliland FD, Baumgartner R, Baumgartner K, Ballard-Barbash R. Physical activity levels among breast cancer survivors. Med Sci Sport Exer. 2004;36(9):1484-91.
19. Segal R, Zwaal C, Green E, Tomasone J, Loblaw A, Petrella T. Exercise for people with cancer: a clinical practice guideline. Curr Oncol. 2017;24(1):40

20. Bellizzi KM, Rowland JH, Jeffery DD, McNeel T. Health behaviors of cancer survivors: examining opportunities for cancer control intervention. J Clin Oncol. 2005;23(34):8884-93.

21. Blanchard CM, Courneya KS, Stein K. Cancer survivors' adherence to lifestyle behavior recommendations and associations with health-related quality of life: results from the American Cancer Society's SCS-II. J Clin Oncol. 2008; 26(13):2198-204

22. Chung JY, Lee DH, Park JH, Lee MK, Kang DW, Min J, Kim DI, Jeong DH, Kim NK, Meyerhardt JA, et al. Patterns of physical activity participation across the cancer trajectory in colorectal cancer survivors. Support Care Cancer. 2013;21(6):1605-12.

23. Jones LW, Courneya KS, Peddle C, Mackey JR. Oncologists' opinions towards recommending exercise to patients with cancer: a Canadian national survey. Support Care Cancer. 2005;13(11):929-37.

24. Godin G, Jobin J, Bouillon J. Assessment of leisure time exercise behavior by self-report: a concurrent validity study. Can J Public Health. 1986;77(5):359-62.

25. Godin G, Shephard RJ. A simple method to assess exercise behavior in the community. Can J Appl Sport Sci. 1985;10(3):141-6.

26. McTiernan A, Friedenreich CM, Katzmarzyk PT, Powell KE, Macko R, Buchner D, Pescatello LS, Bloodgood B, Tennant B, Vaux-Bjerke A, et al. Physical activity in Cancer prevention and survival: a systematic review. Med Sci Sports Exerc. 2019;51(6):1252-61.

27. Aaronson N, Ahmedzia S. Bergman B, al e: the European Organization for Research and Treatment for Cancer QLQ C-30: a quality of life instrument for use in international clinical trials in oncology. J Natl Cancer Inst. 1993:85:365-76.

28. Osoba D, Zee B, Pater J, Warr D, Kaizer L, Latreille J. Psychometric properties and responsiveness of the EORTC quality of life questionnaire (QLQ-C30) in patients with breast, ovarian and lung cancer. Qual Life Res. 1994;3(5):353-64.

29. Osoba D, Rodrigues G, Myles J, Zee B, Pater J. Interpreting the significance of changes in health-related quality-of-life scores. J Clin Oncol. 1998;16(1):139-44.

30. Buffart LM, Thong MS, Schep G, Chinapaw MJ, Brug J, van de Poll-Franse LV. Self-reported physical activity: its correlates and relationship with healthrelated quality of life in a large cohort of colorectal cancer survivors. PLoS One. 2012:7(5):e36164.

31. Peddle CJ, Au HJ, Courneya KS. Associations between exercise, quality of life, and fatigue in colorectal cancer survivors. Dis Colon Rectum. 2008;51(8): 1242-8.

32. Burke S, Wurz A, Bradshaw A, Saunders S, West MA, Brunet J. Physical activity and quality of life in Cancer survivors: a meta-synthesis of qualitative research. Cancers. 2017;9(5):53.

33. Gill DL, Hammond CC, Reifsteck EJ, Jehu CM, Williams RA, Adams MM, Lange EH, Becofsky K, Rodriguez E, Shang Y-T. Physical activity and quality of life. J Prev Med Public Health. 2013;46(Suppl 1):S28.

34. Mishra SI, Scherer RW, Geigle PM, Berlanstein DR, Topaloglu O, Gotay CC, Snyder $C$. Exercise interventions on health-related quality of life for cancer survivors. Cochrane Database Syst Rev. 2012;8:CD007566.

35. Pate RR, Pratt M, Blair SN, Haskell WL, Macera CA, Bouchard C, Buchner D, Ettinger W, Heath GW, King AC, et al. Physical-activity and public-health - a recommendation from the centers-for-disease-control-and-prevention and the American-college-of-sports-medicine. Jama-J Am Med Assoc. 1995; 273(5):402-7.

36. Blanchard CM, Courneya KS, Stein K. American Cancer Society's SCS, II: Cancer survivors' adherence to lifestyle behavior recommendations and associations with health-related quality of life: results from the American Cancer Society's SCS-II. J Clin Oncol. 2008;26(13):2198-204.

37. Park JH, Lee J, Oh M, Park H, Chae J, Kim DI, Lee MK, Yoon YJ, Lee CW, Park $S$. The effect of oncologists' exercise recommendations on the level of exercise and quality of life in survivors of breast and colorectal cancer: a randomized controlled trial. Cancer. 2015;121(16):2740-8.

38. Fehling PC, Smith DL, Warner SE, Dalsky GP. Comparison of accelerometers with oxygen consumption in older adults during exercise. Med Sci Sports Exerc. 1999;31(1):171-5.

39. Jung KW, Park S Fau - Shin A, Shin A Fau - Oh C-M, Oh Cm Fau - Kong H-J, Kong Hj Fau - Jun JK, Jun Jk Fau - Won Y-J, Won YJ: Do female cancer patients display better survival rates compared with males? Analysis of the Korean National Registry data, 2005-2009. (1932-6203 (Electronic)).

\section{Publisher's Note}

Springer Nature remains neutral with regard to jurisdictional claims in published maps and institutional affiliations. 